\title{
Implementation of PSO MPPT Technique for Wind Energy Conversion Systems
}

\author{
M Sravani Durga ${ }^{1}$ | R Ramesh ${ }^{1}$ \\ ${ }^{1}$ Department of EEE, Sri Vani Educational Society Group of Institutions, Chevuturu, Andhra Pradesh, India
}

To Cite this Article

M Sravani Durga and R Ramesh, "Implementation of PSO MPPT Technique for Wind Energy Conversion Systems", International Journal for Modern Trends in Science and Technology, 6(8): 100-103, 2020.

\section{Article Info}

Received on 18-June-2020, Revised on 09-July-2020, Accepted on 27-July-2020, Published on 05-August-2020.

\section{ABSTRACT}

One major advantage of renewable energy is that it is sustainable and will never run out. They provide clean energy because they are non-pollutant and non-contributor to greenhouse effects and global warming. Renewable energy facilities generally require less maintenance than traditional generators. Their fuel being derived from natural and available resources reduces the costs of operation. The proposed PSO algorithm uses the dc current as the perturbing variable. The algorithm detects sudden wind speed changes indirectly through the dc-link voltage slope. The voltage slope is also used to enhance the tracking speed of the algorithm and to prevent the generator from stalling under rapid wind speed slow down conditions. The proposed method uses two modes of operation: A PSO mode with adaptive step size under slow wind speed fluctuation conditions, and a prediction mode employed under fast wind speed change conditions. The dc-link capacitor voltage slope reflects the acceleration information of the generator, which is then used to predict the next step size and direction of the current command.

KEYWORDS: MPPT technique, Solar Energy System, Wind Turbine System

\section{INTRODUCTION}

In the present scenario renewable energy sources are incorporate along with the battery energy storage systems have mostly used for maintain the reliability of power. The number of renewable energy sources is increased as distribution sources; generally, to improve the power supply stability and power quality new strategies of operations are required. The common disadvange of this both wind and solar power plants are as these generate unreliable power [1]. In order to overcome this problem a new technique is implemented i.e maximum power point tracking algorithm which is applicable to both wind and solar plants. Dynamic performance of a wind and solar system is analyzed. There are some previous works on hybrid systems comprising of wind energy, photovoltaic and fuel cell have been discussed. All the energy sources are modeled using MATLAB software tool to analyze their behavior. A simple control method tracks the maximum power from the wind/solar energy source to achieve much higher generating capacity factors. The simulation results prove the feasibility and reliability of this proposed system [2]-[3]. 


\section{PROPOSED HYBRID ENERGY SYSTEM}

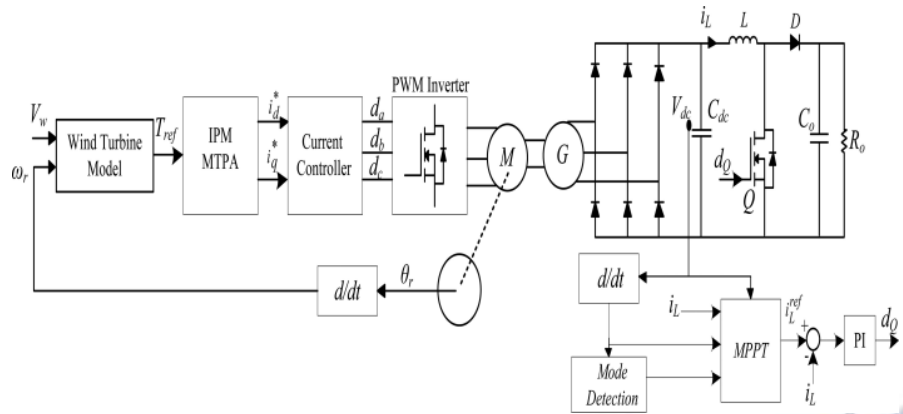

Figure 1: Configuration of Wind Energy System with MPPT

The schematic of the WECS to which the MPPT algorithm will be applied is shown in Fig. 1. The wind turbine is directly coupled to the PMSG. Compared to other generators, the PMSG has the advantage of being directly coupled to a wind turbine with no need for a gear box; there is no need for excitation current as in the doubly fed induction generator (DFIG) case, and there is no direct connection between the generator and the grid for grid tie applications. The load Ro can be replaced by a unity power factor inverter that supplies a standalone ac load or is connected to the utility grid. In this paper, a resistor is used as the load, and the MPP will be reflected into maximum voltage across it. The diode bridge rectifier is used rather than a three-phase controlled PWM rectifier because of its lower cost and higher reliability. The boost converter consisting of the inductor $\mathrm{L}$, the diode $\mathrm{D}$, and the switch $\mathrm{Q}$ will be current controlled to track the MPP and boost the voltage across the load resistor.

\section{WIND TURBINE}

Wind turbines square measure classified into 2 general types: Horizontal axis wind turbine and Vertical axis wind turbine. A vertical axis wind machine has its blades rotating on axis perpendicular to the bottom. The square measure variety of obtainable styles for each and every kind has bound benefits and downsides.

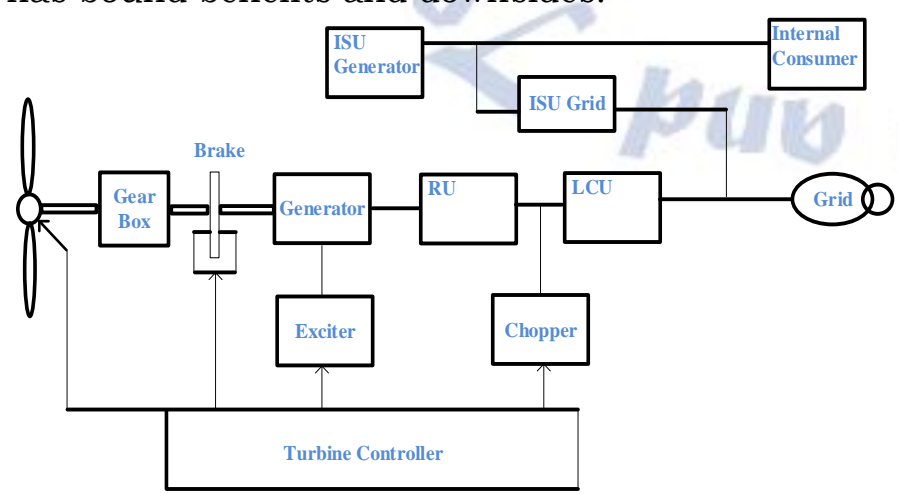

Figure 2: Basic Wind Turbine System
The wind turbines with a squirrel cage generator are equipped with a soft starter mechanism for reactive power compensation as coop generators consume reactive power. This generator and also the turbine rotor area unit coupled through a shell, because the best rotor and generator speed ranges are totally different.

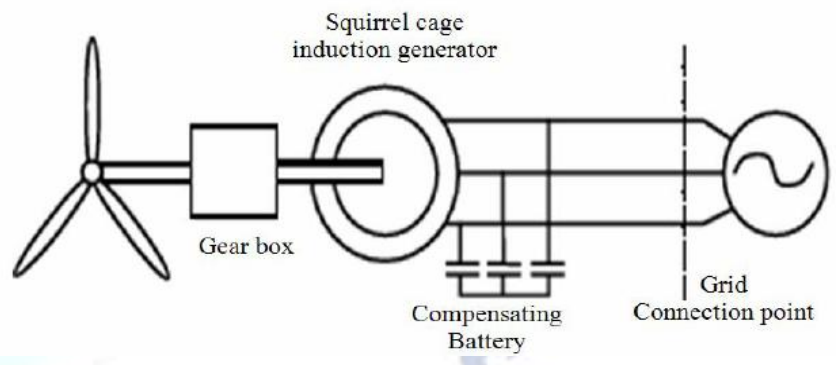

Figure 3: SCIG based WES

\section{Control Algorithm}

The solar converter, is nothing but a DC-DC boost converter which is used to regulate solar power with MPPT control diagram. In this paper a cuckoo based MPPT technique is proposed. The control diagram for DC-DC boost converter is shown in Fig. 4. As the solar panel voltage / current increases, the PWM generator increases its repetition rate thus resulting in increased output current. At the same time, additional voltage is applied to the inductor thus increasing its charge current. Where the initialization is based on voltage and power calculations that are based on current and voltage values acquired from sensors [9]. Once the actual power is calculated, then the next cycle of the measurement is compared to previous value to change the reference voltage $V_{\text {ref. }}$.

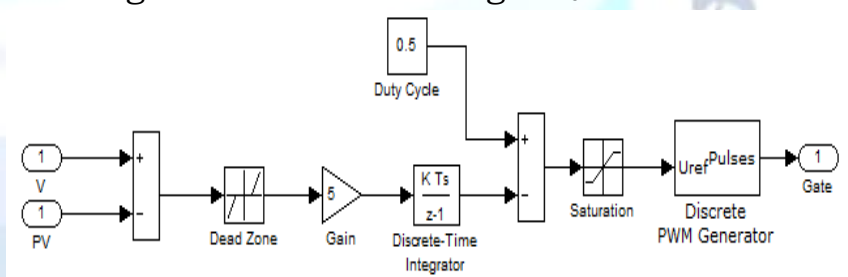

Fig. 4. DC-DC converter MPPT Controller Particle Swarm Optimization

The swarm intelligence technique is one of the artificial intelligences, this technique is based on collective behavior of decentralized and self-organized systems. The main advantage to apply this proposed optimization technique to hybrid system is to get less oscillations in system as compared with conventional $\mathrm{P} \& \mathrm{O}$ method. As per literature survey, previously PSO technique as applied to only photovoltaic system for extracting maximum power. These techniques generally made up of population of simple agents interacting locally with one another and with their environment. Particle Swarm Optimization 
technique can be used to find the approximate solutions to extremely difficult or impossible numeric maximization and minimization problems. PSO is initialized with a group of random particles and then searches for optimal by updating generations. Particles move through the solution space, and are evaluated according to some fitness criterion after each time step. In every iteration, each particle is updated by following two "best" values. The first one is the best solution (fitness) it has achieved so far (the fitness value is also stored). This value is called $\mathrm{P}_{\text {best. }}$ Another "best" value that is tracked by the particle swarm optimizer is the best value obtained so far by any particle in the population. This second-best value is a global best and called gbest. When a particle takes part of the population as its topological neighbors, the second-best value is a local best and is called $L_{\text {best. }}$. Neighborhood bests allow parallel exploration of the search space and reduce the susceptibility of PSO to falling into local minima, but slow down convergence speed.

Each particle tries to modify its current position and velocity according to the distance between its current position and $\mathrm{P}_{\text {best}}$, and the distance between its current position and $g_{\text {best }}$.

$v_{n+1}=v_{n}+c_{1}$ rand 1()$*\left(P_{b e s t, n}-\right.$ CurrentPosition $\left._{n}\right)+c_{2}$ ran

Where, $\mathbf{v}_{\mathbf{n}+1}$ : Velocity of particle at $(n+1)^{\text {th }}$ iteration

$\mathbf{V}_{\mathbf{n}}$ : Velocity of particle at $n^{\text {thiteration }}$

$\mathbf{c}_{1}$ : acceleration factor related to $\mathrm{g}_{\text {best }}$

c2: acceleration factor related to $\mathrm{L}_{\mathrm{best}}$

rand1( ): random number between 0 and 1

rand2( ): random number between 0 and 1

gbest: gbest position of swarm

Pbest: $_{\text {best }}$ position of particle

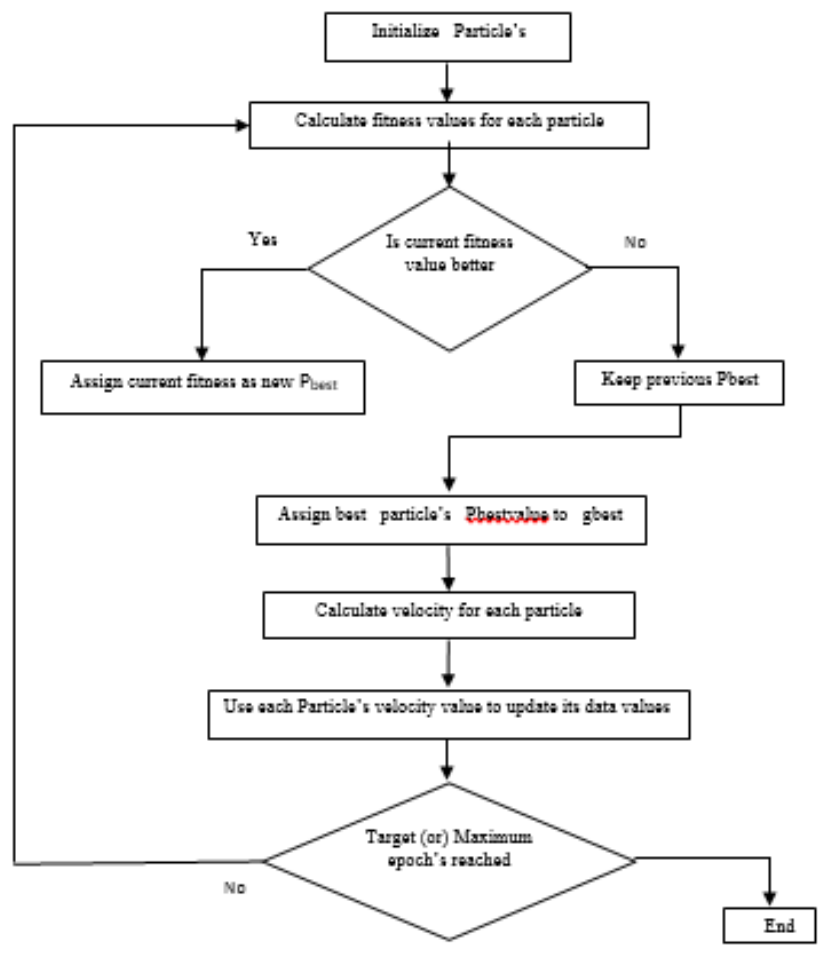

Fig. 5. Algoritham for PSO Technique

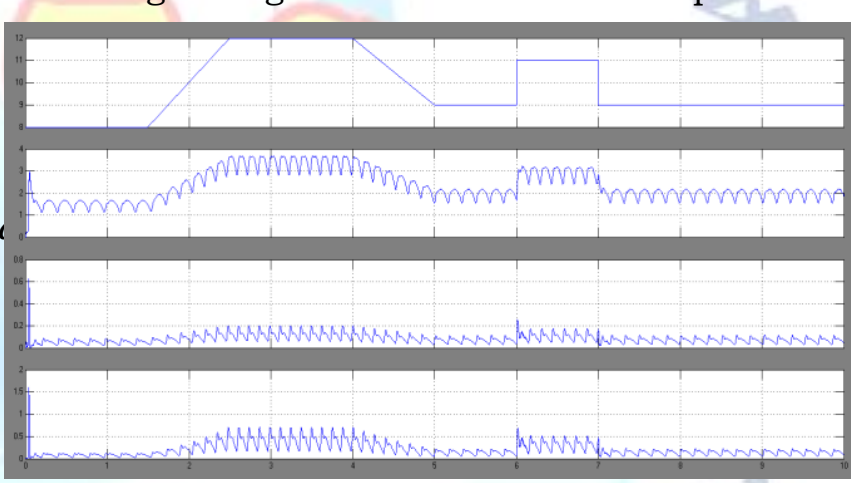

Figure 6: Simulation result for (a) wind speed, (b) DC voltage, (c) DC current and (d) wind DC power

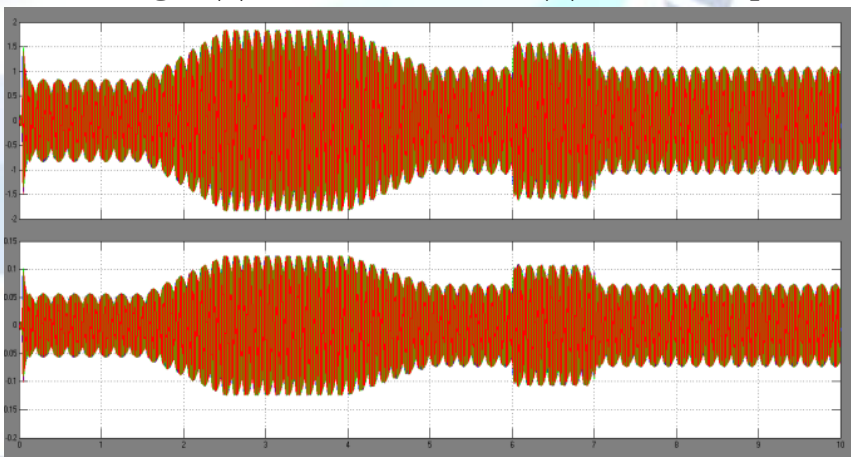

Figure 7: Simulation result for load voltage and current 


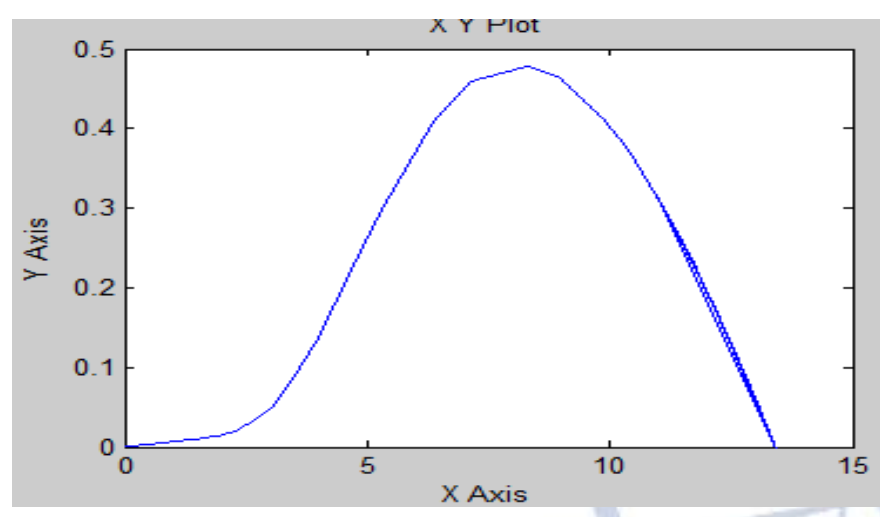

Figure 8: Simulation graph between CP VS TSR ratio

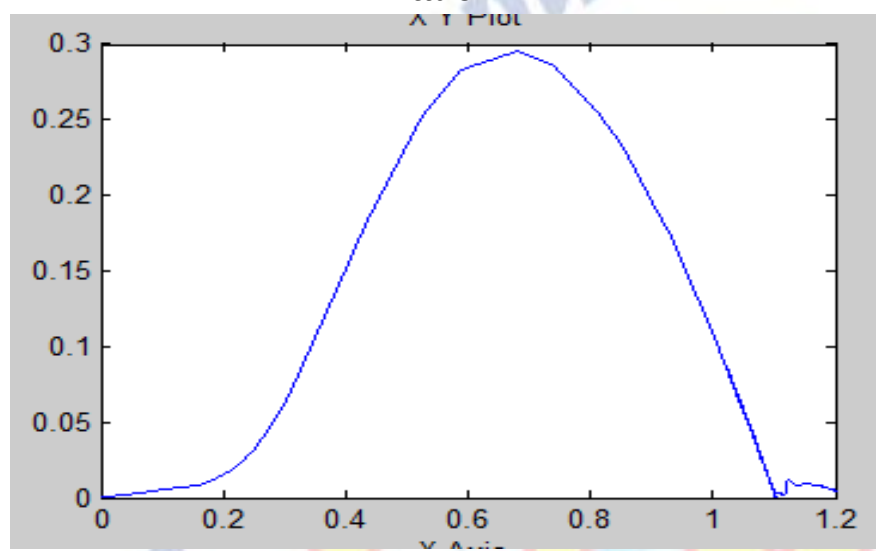

Figure 9: Simulation graph between Power VS rotor speed with small step change

\section{CONCLUSION}

In this paper, a MPPT algorithm for small-scale WECS has been proposed. The algorithm uses the dc-side current as the perturbing variable, while the dc-link voltage slope information is utilized to detect fast wind speed change. Based on the wind conditions, the algorithm works on one of two modes of operation: normal PSO mode under slow varying wind speed conditions. In this mode, the algorithm finely tune to the MPP as long as the wind speed is slowly varying or steady. The other mode of operation is the prediction mode under fast wind speed change conditions. And this mode is responsible for bringing the operating point near the MPP whenever the wind speed rapidly changes in speed or direction. This proposed mode of operation prevents the generator from stalling under sudden wind speed slowdown scenario as well, where conventional PSO methods may fail under this scenario due to their slow response. The step size of the perturbing variable is chosen to be a scaled measure of the voltage slope while in the prediction mode and of the power increment while in the normal PSO mode.

\section{REFERENCES}

[1] Joanne Hui*, Alireza Bakhshai, and Praveen K. Jain, "A Hybrid Wind-Solar Energy System: A New Rectifier Stage Topology ", in Applied Power Electronics Conference and Exposition (APEC), 2010 Twenty-Fifth Annual IEEE, pp 156-161, 21-25 Feb. 2010

[2] S.K. Kim, J.H Jeon, C.H. Cho, J.B. Ahn, and S.H. Kwon, "Dynamic Modeling and Control of a Grid-Connected Hybrid Generation System with Versatile Power Transfer," IEEE Transactions on Industrial Electronics, vol. 55, pp. 1677-1688, April 2008.

[3] N. A. Ahmed, M. Miyatake, and A. K. Al-Othman, "Power fluctuations suppression of stand-alone hybrid generation combining solar photovoltaic/wind turbine and fuel cell systems," in Proc. Of Energy Conversion and Management, Vol. 49, pp. 2711-2719, October 2008.

[4] Wind and Solar Power Systems Design Analysis and Operation Second Edition, by Mukund R. Patel, Taylor \& Francis Group Publishing Co.

[5] Y.M. Chen, Y.C. Liu, S.C. Hung, and C.S. Cheng, "Multi-Input Inverter for Grid-Connected Hybrid PV/Wind Power System," IEEE Transactions on Power Electronics, vol. 22, May 2007.

[6] S. Jain, and V. Agarwal, "An Integrated Hybrid Power Supply for Distributed Generation Applications Fed by Nonconventional Energy Sources," IEEE Transactions on Energy Conversion, vol. 23, June 2008.

[7] D. Das, R. Esmaili, L. Xu, D. Nichols, "An Optimal Design of a Grid Connected Hybrid Wind/Photovoltaic/Fuel Cell System for Distributed Energy Production," in Proc. IEEE Industrial Electronics Conference, pp. 2499-2504, Nov. 2005.

[8] Dos Reis, F.S., Tan, K. and Islam, S., "Using PFC for harmonic mitigation in wind turbine energy conversion systems" in Proc. of the IECON 2004 Conference, pp. 31003105, Nov. 2004

[9] R. W. Erickson, "Some Topologies of High Quality Rectifiers" in the Proc. of the First International Conference on Energy, Power, and Motion Control, May 1997.

[10] D.S.L. Simonetti, J.Sebastian, and J.Uceda, "The Discontinuous Conduction Mode". 